Int. J. Electrochem. Sci., 14 (2019) 9838 - 9849

\title{
Milled-Si@C Composites as Potential Anode Materials for Li- ion Batteries
}

\author{
Hong Lv $v^{1, *}$, Sen Wang ${ }^{1}$, Guanghui Zhang ${ }^{1}$, Dabin Wang ${ }^{2}$, Wei Zhou ${ }^{1}$, Bing Li ${ }^{1}$, Minzhe Xue ${ }^{1}$, \\ Cunman Zhang ${ }^{1, *}$ \\ ${ }^{1}$ Clean Energy Automotive Engineering Center \& School of Automotive Studies, 4800 Caoan Road, \\ Tongji University, Shanghai 201804, China \\ ${ }^{2}$ Australian Centre for Electromaterials Science, School of Chemistry, Monash University, Clayton, \\ VIC 3800, Australia \\ *E-mail: 1vhong@tongji.edu.cn, zhangcunman@tongji.edu.cn
}

doi: $10.20964 / 2019.10 .31$

Received: 30 May 2019 / Accepted: 29 July 2019 / Published: 30 August 2019

Silicon ( $\mathrm{Si}$ ) has been identified as having high potential for lithium-ion battery anodes because of its ultrahigh capacity. However, its dramatic volume change in the process of lithiation/delithiation and its intrinsically poor electrical conductivity have severely inhibited its practical application. Herein, micron-sized Si alloys with carbon shells are prepared by high-energy ball milling coupled with an evaporation self-assembly method. A high and stable specific capacity of $850.5 \mathrm{mAh} / \mathrm{g}$ is achieved over 50 cycles and held at $650 \mathrm{mAh} / \mathrm{g}$ after 350 cycles with a coulombic efficiency $>99.8 \%$. The highly improved performance could be attributed to the unique microstructure of the as-synthesized composite materials in which crystalline Si nanoparticles are embedded in amorphous $\mathrm{Si}-\mathrm{M}_{2} \mathrm{O}_{3}(\mathrm{M}=$ $\mathrm{Al}$ and $\mathrm{Si}$ ) matrix phases with a carbon shell on the surface, thereby achieving better buffering capacity and conductivity. The results we obtained could pave the way for using silicon as anodes for lithiumion batteries.

Keywords: Silicon, Si@C Composites, Lithium-ion battery, anode, specific capacity

\section{FULL TEXT}

(C) 2019 The Authors. Published by ESG (www.electrochemsci.org). This article is an open access article distributed under the terms and conditions of the Creative Commons Attribution license (http://creativecommons.org/licenses/by/4.0/). 